\title{
Ground-level predation on artificial caterpillars indicates no enemy-free time for lepidopteran larvae
}

\author{
M. Ferrante ${ }^{1,5}$, G. Barone ${ }^{1,2}$, M. Kiss ${ }^{1,3}$, E. Bozóné-Borbáth ${ }^{1,4}$ and G. L. Lövei ${ }^{1}$ \\ ${ }^{1}$ Department of Agroecology, Aarhus University, Flakkebjerg Research Centre, Forsøgsvej 1, DK4200 Slagelse, \\ Denmark \\ ${ }^{2}$ University of Palermo, Department of Biological, Chemical and Pharmaceutical Sciences and Technologies, \\ 16 Viale delle Scienze, I- 90128, Palermo, Italy \\ ${ }^{3}$ University of Agricultural Sciences and Veterinary Medicine, Faculty of Horticulture, 3-5/Manastur, Cluj-Napoca, \\ Romania \\ ${ }^{4} 10$ Battonyai street, $H$ - 5744 Kevermes, Hungary \\ ${ }^{5}$ Corresponding author. E-mail: marco.ferrante@live.it
}

Keywords: Aposematic coloration, Defensive colouration, Ecosystem service, Foraging behaviour, Mortality, Sentinel prey, Temperate forest.

\begin{abstract}
Lepidoptera is one of the most diverse orders of insects, their larvae are very abundant in many habitats, and frequent prey of various predators. To decrease predation risk, caterpillars developed several means of defence, among them timing their activity to avoid predators (seeking enemy-free time). Although the enemy-free time hypothesis is often invoked to explain caterpillar behaviour, empirical evidence for it is scarce. We tested whether such enemy-free time exists in a temperate forest by comparing predation pressure on artificial caterpillars during day and night on the ground in forest fragments in Denmark. We found a high predation rate, $23.9 \% \mathrm{~d}^{-1}$, and higher predation rate at night $\left(30.9 \% \mathrm{~d}^{-0.5}\right)$ than during the day $\left(17.0 \% \mathrm{~d}^{-0.5}\right)$, both by invertebrate $\left(23.3 \% \mathrm{~d}^{-0.5}\right.$ vs. $\left.12.4 \% \mathrm{~d}^{-0.5}\right)$ and vertebrate $\left(8.5 \% \mathrm{~d}^{-0.5}\right.$ vs. $\left.3.3 \% \mathrm{~d}^{-0.5}\right)$ predators. The most important predators were chewing insects $\left(73.4 \%\right.$ of all attacks) and small mammals $(19.0 \%)$. Attack rates on red caterpillars were higher $\left(30.0 \% \mathrm{~d}^{-1}\right)$ than on green ones $\left(19.5 \% \mathrm{~d}^{-1}\right)$. Overall, these data do not support the idea that night activity can provide enemy-free time for solitary caterpillars on the temperate forest floor.
\end{abstract}

Abbreviations: GG - Green-Green; GR - Green-Red; RR - Red-Red.

\section{Introduction}

The evolutionary success of holometaboly is reflected by the astonishing diversity of holometabolous insects (Yang 2001). Such insects, however, have to go through life stages that are highly vulnerable to predators, either because of their immobility (eggs, pupae) or for their soft chitinisation (larvae). Lepidoptera is one of the most diverse orders of insects (New 2013); their larvae (caterpillars) are very abundant in many habitats, and frequent prey of various predators (James et al. 2017). The use of sentinel prey revealed that caterpillars can suffer extremely high predation rates (Lövei and Ferrante 2017, Mira and Bernays 2002); both from invertebrate (Ferrante et al. 2014) and vertebrate predators (Bereczki et al. 2014). In order to protect themselves, caterpillars have evolved a great variety of strategies, which range from behavioural (e.g., leaf-rolling, Tvardikova and Novotny 2012) to morphological (e.g., spines, colouration, Greeney et al. 2012), and chemical (e.g., sequestration of terpenes, Opitz and Müller 2009) means of defence.

These defences notwithstanding, many caterpillars remain vulnerable, and can also time their activity to avoid predators (seeking enemy-free time, Novotny et al. 1999). Theoretically, the enemy-free time hypothesis could explain why non-aposematic caterpillars choose not to feed during the day (Heinrich 1979), even if this incurs developmental costs (Seifert et al. 2016). Predation rates in the tropical forest canopy in Amazonia (Seifert et al. 2016) and Papua New Guinea (Novotny et al. 1999) support this hypothesis: attack rates on caterpillars are much higher during the day than during the night. Although caterpillars spend their time feeding on vegetation above ground, they also frequently occur on the ground. They can drop in reaction to a predator attack (Cain 1985), change host plants (Jones 1977), or seek pupation or overwintering sites (Kenne and Dejean 1999) in the soil. During these times, they are at risk from ground-active predators. In Cameroon, up to $91.5 \%$ of the caterpillars of the noctuid Achea catocaloides descending from the host tree to pupate are killed by ants (Kenne and Dejean 1999). Consequently, ground-level predation pressure is potentially important for caterpillars, yet rarely studied.

Moreover, the timing of activity may not be independent from other defensive strategies, such as colouration, the effectiveness of which depends on the predator's ability to perceive colours (Ruxton et al. 2004). Defensive colouration, be that aposematic (signalling toxicity/unpalatability, Gittleman and Harvey 1980) or cryptic (matching the background to reduce detection, Skelhorn et al. 2010) requires different con- 
ditions to be effective. Supposedly, aposematic colouration works better during daytime when better visibility makes it more apparent. Cryptically coloured species may be inactive during the day, and active during the night. Therefore, different foraging time for aposematic and cryptic caterpillars can be expected. Evidence for this is mixed, however. Larvae of two butterfly species, the cryptic Pieris rapae and the aposematic Euphydryas phaeton show no differences in their diurnal patterns of feeding (Heinrich 1979, Edwards and Wratten 1983, Mauricio and Bowers 1990). Quantitative data on predation rates on caterpillars possessing these alternative strategies would contribute to a better understanding of prey behaviour, but direct comparisons are rare (Carroll and Sherratt 2013).

The artificial caterpillar method is a simple technique to quantify predation rates (Howe et al. 2009); additionally, it allows the identification of predators (Lövei and Ferrante 2017), albeit with varying levels of resolution (Low et al 2014). Artificial caterpillars have been used to investigate the effectiveness against birds of defensive colourations or patterns, such as eyespots (Hossie and Sherratt 2012, 2013, Hossie et al. 2015), masquerade (Suzuki and Sakurai 2015), or countershading (Rowland et al. 2007, 2008). However, predators that use visual cues when hunting includes not only mammals but also insects such as ground beetles (Lövei and Sunderland 1996), wasps and mantids (Greeney et al. 2012). Their reaction to differently coloured prey is less well studied. Both vertebrates and invertebrates are important caterpillar predators in temperate forests (Remmel et al. 2012), where predation rates on caterpillars are usually high, both at ground (Ferrante et al. 2014) and canopy (Mäntylä et al. 2008, 2014) levels.

We compared day- and night-time predation rates on the temperate forest floor using artificial plasticine caterpillars with cryptic (green) and aposematic (red) colours (Stevens and Ruxton 2012). Even though not every vertebrate (Yokoyama and Radlwimmer 2001) nor invertebrate (Salcedo et al. 2003) predator can detect red colour per se, the detectability of aposematic colouration is mainly based on colour contrast (Stevens and Ruxton 2012, Aronsson and Gamberale-Stille 2009). Moreover, the range of visible colours has never been investigated for most arthropods, and is often generalised from studies on the few species examined, although the visual abilities of even closely-related species can be very different (Théry and Gomez 2010). Although aposematism is frequently linked to contrasting patterns (Aronsson and Gamberale-Stille 2009), we chose to use uniform-coloured prey, because a preliminary experiment indicated that uniform red plasticine caterpillars did not suffer significantly different predation than ones with a contrasting pattern (black and red stripes, Fig. S2, see Appendix A1). These results are in accordance with a previous study that found internal contrast to affect predators less than background contrast (Aronsson and Gamberale-Stille 2009).

We tested the following hypotheses: H1 - predation at nighttime is higher than during daytime, because several important predator groups, among them chewing arthropods and small mammals, are often night-active, at least in our experimental area, forested habitats in Denmark (Ferrante et al. 2014). We also hypothesised that $\mathrm{H} 2$ - during daytime, attack rates on caterpillars with aposematic colouration is lower than on cryptic ones, while $\mathrm{H} 3$ - we expected no significant differences between attack rates on the different colourations at night.

We found that both invertebrate and vertebrate predation rates were significantly higher at night than during daytime, confirming our H1. However, there was no significant interaction between prey colouration and exposure time; invertebrate predation rates were significantly higher on red (aposematic) than on green (cryptic) prey, while vertebrate predation rate was significantly higher on green than red artificial prey.

\section{Materials and methods}

\section{Study site and artificial caterpillars}

Our study sites were near the Flakkebjerg Research Station ( $55^{\circ} 34^{\prime} \mathrm{N}, 11^{\circ} 34^{\prime} \mathrm{E}, 34 \mathrm{~m}$ a.s.l.) belonging to Aarhus University, in the western region of Zealand, Denmark. The three selected sites were in forest patches (0.3-0.7 ha, situated at least $500 \mathrm{~m}$ from each other) characterised by the presence of beech (Fagus sylvatica L.) mixed with a few poplar (Populus sp.) and plane trees (Platanus sp.). In order to quantify predation, we used artificial caterpillars $15 \mathrm{~mm}$ long and $3 \mathrm{~mm}$ of diameter made of green and red plasticine (Smeedi plus, Denmark), produced using a garlic press as described by Howe et al. (2009).

\section{Experimental design}

Our unit of prey consisted of a pair of artificial caterpillars, placed on the ground about $5 \mathrm{~cm}$ from each other; the two caterpillars were considered as a single prey item. We used three combinations: green-green (GG), red-red (RR), green-red (GR), simulating respectively cryptic, aposematic, and mixed colouration. In order to guarantee independence among these, the three pairs of a patch were placed at $5 \mathrm{~m}$ from each other in a triangular arrangement. At each site, we established ten such patches $(n=30$ independent sentinels per site by sampling event), each of them at least $10 \mathrm{~m}$ from each other (Fig. S1). Caterpillars were prepared in the laboratory and glued to pieces of bamboo for easy handling, and placed on the forest litter between 7:00-9:00 a.m. To obtain data on predation during daytime and nighttime, they were checked directly in the field using a magnifying glass $(12 \times$ magnification) $12 \mathrm{~h}$ and $24 \mathrm{~h}$ later. After the first check (i.e., after $12 \mathrm{~h}$ exposure), predated or missing sentinels were replaced with new ones; after $24 \mathrm{~h}$, all caterpillars were removed. We defined the prey "predated" if at least one of them had an attack mark. Multiple attack marks by the same kind of predator were considered as a single attack, but multiple bites by different predators were classified as independent attacks. In case of doubt, predation marks were re-checked in the laboratory under a stereomicroscope (Leica MS5, 6.3-40× magnifi- 
cation), and identified using published records (Howe et al. 2009, Low et al. 2014). During July-August 2015, we carried out four sampling events, including a pilot study using only two sites, exposing a total of 660 pairs of artificial caterpillars. Considering the long summer days in Denmark, (L:D $\sim 16 \mathrm{~h}: 8 \mathrm{~h}$ ), our prey exposure periods were $12 \mathrm{~h}$ daylight ("day") and $4 \mathrm{~h}$ light $+8 \mathrm{~h}$ darkness ("night"). We note that in the temperate region during summer, nighttime does not necessarily mean complete darkness. In Denmark, between the end of July and beginning of August, astronomical twilight persists throughout the night (https://www.timeanddate. $\mathrm{com} /$ sun/denmark/copenhagen?month=7), and predators with higher sensitivity to light may be still able to perceive colours (Kelber and Roth 2006, Warrant and Dacke 2011).

\section{Statistical analysis}

No prey unit was lost, but marks by snails and slugs ( $\mathrm{n}$ =26) were excluded from the analyses. Differences in total predation (expressed as \% of prey units attacked) between day and night and between colourations were tested using the Wilcoxon Signed-Rank test on the mean predation rates. As invertebrate and vertebrate predators detect colours differently (Cronin et al. 2014), their predation rates were analysed using two separate logistic regressions. The initial models were full ones, including colouration (GG, RR, and GR), time (daytime or nighttime), and the interaction between colouration and time as fixed effects, and study site as random effect. Backward model selection was done by comparing the Akaike Information Criterion values (Akaike 1998). For both predator groups, the models without interaction were the best ones (Tables S1, S2). We used the post-hoc Tukey test to determine the significance of the results. All statistical analyses were performed using the statistical program $\mathrm{R}$, version 3.1.1 (R Core Team 2015), and the package lme4 (Bates et al. 2015).

\section{Results}

Of the artificial caterpillars, $23.9 \%$ (158/660) showed signs of predation after $24 \mathrm{~h}$; predators included chewing insects, ants, small mammals and birds (Fig. 1). More marks were attributable to invertebrates (chewing insects $73.4 \%$ of the attacks, ants $1.9 \%$ ), than to vertebrates (small mammals $19.6 \%$, birds $5.1 \%$ ); the predator identity of $5.1 \%$ of attacks remained unknown. Multiple bites by different predators accounted for $6.3 \%$ of the attacks.

Total predation was significantly higher (Wilcoxon test: $\mathrm{W}=46860, \mathrm{P}<0.001)$ during the period including the night (mean $=30.9 \% \mathrm{~d}^{-0.5}, \mathrm{SD}=46.3 \% \mathrm{~d}^{-0.5}, \mathrm{~N}=330$ ) than during the day $\left(\right.$ mean $\left.=17.0 \% \mathrm{~d}^{-0.5}, \mathrm{SD}=37.6 \% \mathrm{~d}^{-0.5}, \mathrm{~N}=330\right)$. Red dummy caterpillars were attacked significantly more frequently $\left(\right.$ mean $=30.0 \% \mathrm{~d}^{-1}, \mathrm{SD}=45.9 \% \mathrm{~d}^{-1}, \mathrm{~N}=220$; Wilcoxon test: $\mathrm{W}=21670, \mathrm{P}=0.01)$ than green $\left(\right.$ mean $=19.5 \% \mathrm{~d}^{-1}, \mathrm{SD}=$ $39.7 \% \mathrm{~d}^{-1}, \mathrm{~N}=220$ ), but there were no significant differences between either of these and mixed colouration (mean $=22.3 \% \mathrm{~d}^{-1}, \mathrm{SD}=41.7 \% \mathrm{~d}^{-1}, \mathrm{~N}=220$; Wilcoxon test: $\mathrm{W}=$ $22330 / 23540, \mathrm{P}=0.065-0.483)$.
Table 1 Mean rates $\left(\% \mathrm{~d}^{-0.5} \pm \mathrm{SD}\right)$ of invertebrate and vertebrate predation on artificial caterpillars during day- vs. nighttime exposure in three deciduous forest patches at Flakkebjerg, Denmark. Sample size was $N=110$ for all combinations.

\begin{tabular}{llrr}
\hline \multirow{2}{*}{ Prey colouration } & $\begin{array}{l}\text { Exposure } \\
\text { period }\end{array}$ & \multicolumn{2}{c}{ Predation $\left(\% \mathrm{~d}^{-0.5}\right)$ by } \\
\cline { 3 - 4 } & & $5.5 \pm 22.8$ & $6.4 \pm 24.5$ \\
\hline Green-Green & Day & $17.3 \pm 38.0$ & $11.8 \pm 32.4$ \\
& Night & $12.7 \pm 33.5$ & $2.7 \pm 16.4$ \\
Green-Red & Day & $23.6 \pm 42.7$ & $6.4 \pm 24.5$ \\
& Night & $19.1 \pm 39.5$ & $0.9 \pm 9.5$ \\
Red-Red & Day & $29.1 \pm 45.6$ & $7.3 \pm 26.1$ \\
\hline
\end{tabular}

Invertebrate predation rates were almost always higher than vertebrate ones, with the only exception of attacks on green (GG) caterpillars during the day (Table 1).

Invertebrate predation rates were significantly higher (Tukey's test, $\mathrm{Z}=3.732, \mathrm{P}<0.001$ ) during the night (mean $=23.3 \% \mathrm{~d}^{-0.5}, \mathrm{SD}=42.4 \% \mathrm{~d}^{-0.5}, \mathrm{~N}=330$ ) than during the day $\left(\right.$ mean $\left.=12.4 \% \mathrm{~d}^{-0.5}, \mathrm{SD}=33.0 \% \mathrm{~d}^{-0.5}, \mathrm{~N}=330\right)$. Invertebrate predation on red caterpillars (mean $=24.1 \% \mathrm{~d}^{-1}, \mathrm{SD}=42.9 \% \mathrm{~d}^{-1}$, $\mathrm{N}=220$ ) was significantly higher (Tukey's test: $\mathrm{Z}=3.550$, $\mathrm{P}=0.001)$ than on green ones $\left(\right.$ mean $=11.4 \% \mathrm{~d}^{-1}, \mathrm{SD}=$ $31.8 \% \mathrm{~d}^{-1}, \mathrm{~N}=220$ ), but there was no significant difference between predation on mixed-colour pairs $\left(\right.$ mean $=18.2 \% \mathrm{~d}^{-1}$, $\mathrm{SD}=38.7 \% \mathrm{~d}^{-1}, \mathrm{~N}=220$ ) and the other two combinations (Tukey's test: $\mathrm{Z}=1.578$ and $\mathrm{Z}=2.064, \mathrm{P}=0.254$ and $\mathrm{P}=$ 0.097).

Vertebrate predation rates during the night (mean = $8.5 \% \mathrm{~d}^{-0.5}, \mathrm{SD}=27.9 \% \mathrm{~d}^{-0.5}, \mathrm{~N}=330$ ) were also significantly higher (Tukey's test: $\mathrm{Z}=2.724, \mathrm{P}=0.006$ ) than during the day (mean $=3.3 \% \mathrm{~d}^{-0.5}, \mathrm{SD}=18.0 \% \mathrm{~d}^{-0.5}, \mathrm{~N}=330$ ), but there was no significant difference (Tukey's test: $\mathrm{Z}=-2.076, \mathrm{Z}=$ $-1.870, \mathrm{Z}=-0.235$, and $\mathrm{P}=0.129, \mathrm{P}=0.199, \mathrm{P}=0.994$, respectively) among the attack rates on prey of different colouration (Fig. 2).

\section{Discussion}

We found that at our study sites in Danish deciduous forest fragments, invertebrates rather than vertebrates were the main predators at ground level, as indicated by attack rates on our artificial caterpillars. This is consistent with previous records (Ferrante et al. 2014), but the registered predation rate was higher than the global median predation rate in temperate forests (Lövei and Ferrante 2017). We also found numerous marks by small mammals, which are usually not considered an important source of arthropod mortality in temperate areas (Remmel et al. 2011). The low frequency of bird attacks may be a consequence of the prey arrangement, as most birds in these habitats search their prey on branches and leaves (Berecki et al. 2014). 
In this experiment, total predation rate was higher during the night than the day (H1 accepted), while the opposite was registered in Amazonia (Seifert et al. 2016), and Papua New Guinea (Novotny et al. 1999). Even though the sentinels in those experiments were placed on foliage (while ours were at ground level), we think that differences in the identity, be- haviour and density of the main predators in the respective study areas could better explain the registered differences in predation rates. Ants dominate in tropical habitats, and are a prominent predatory group. In the Amazonian rainforest of French Guiana, ants (mostly Crematogaster sp.), active both during daytime and at night (Menzi 1987), were the most

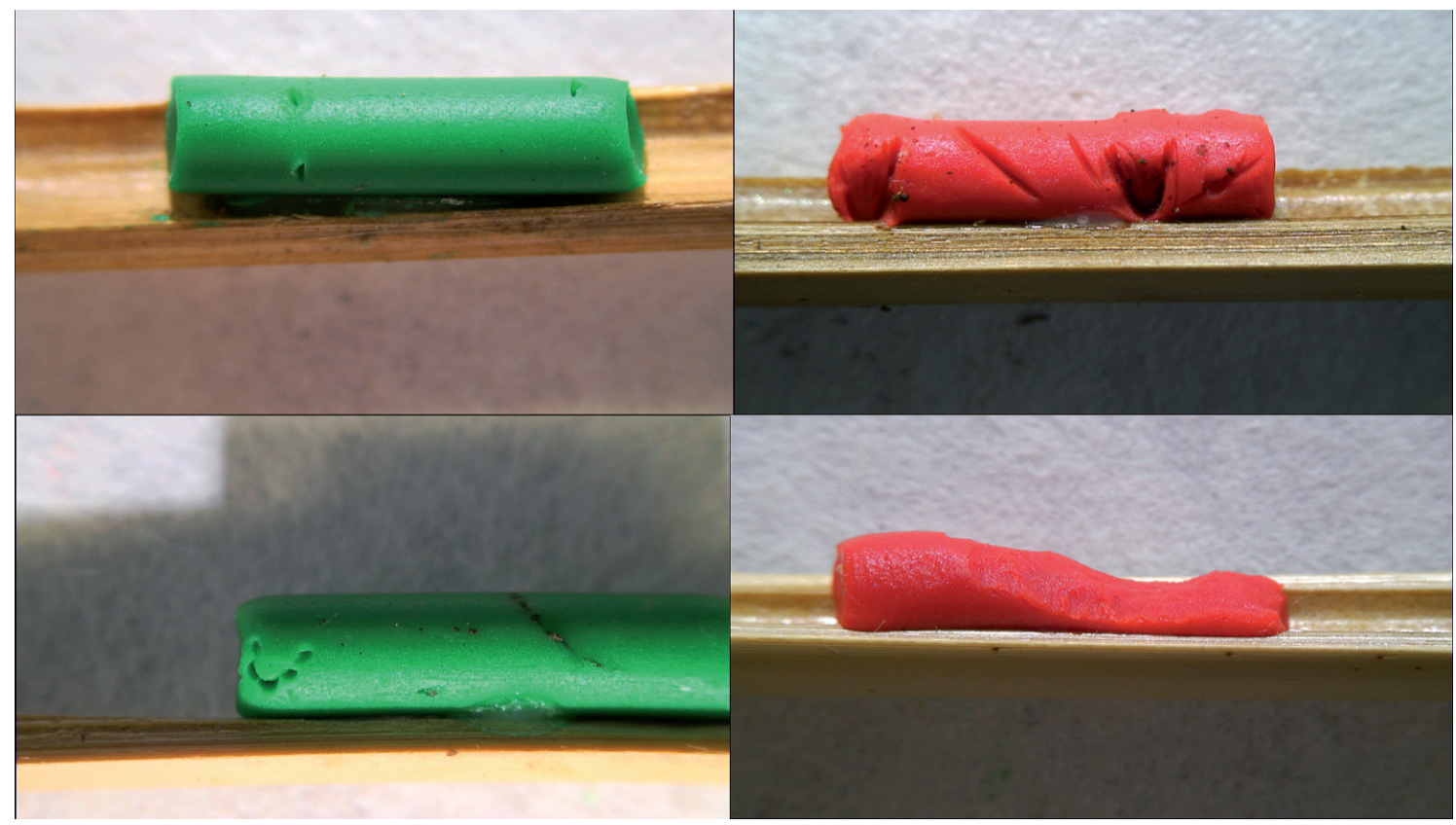

Figure 1. Artificial caterpillars showing signs of predation. Predation marks by different predators on green and red artificial caterpillars exposed at ground level in forest fragments near Flakkebjerg, Denmark. Clockwise from top left: chewing insect, bird, slug (not considered as a predator), and small mammal.

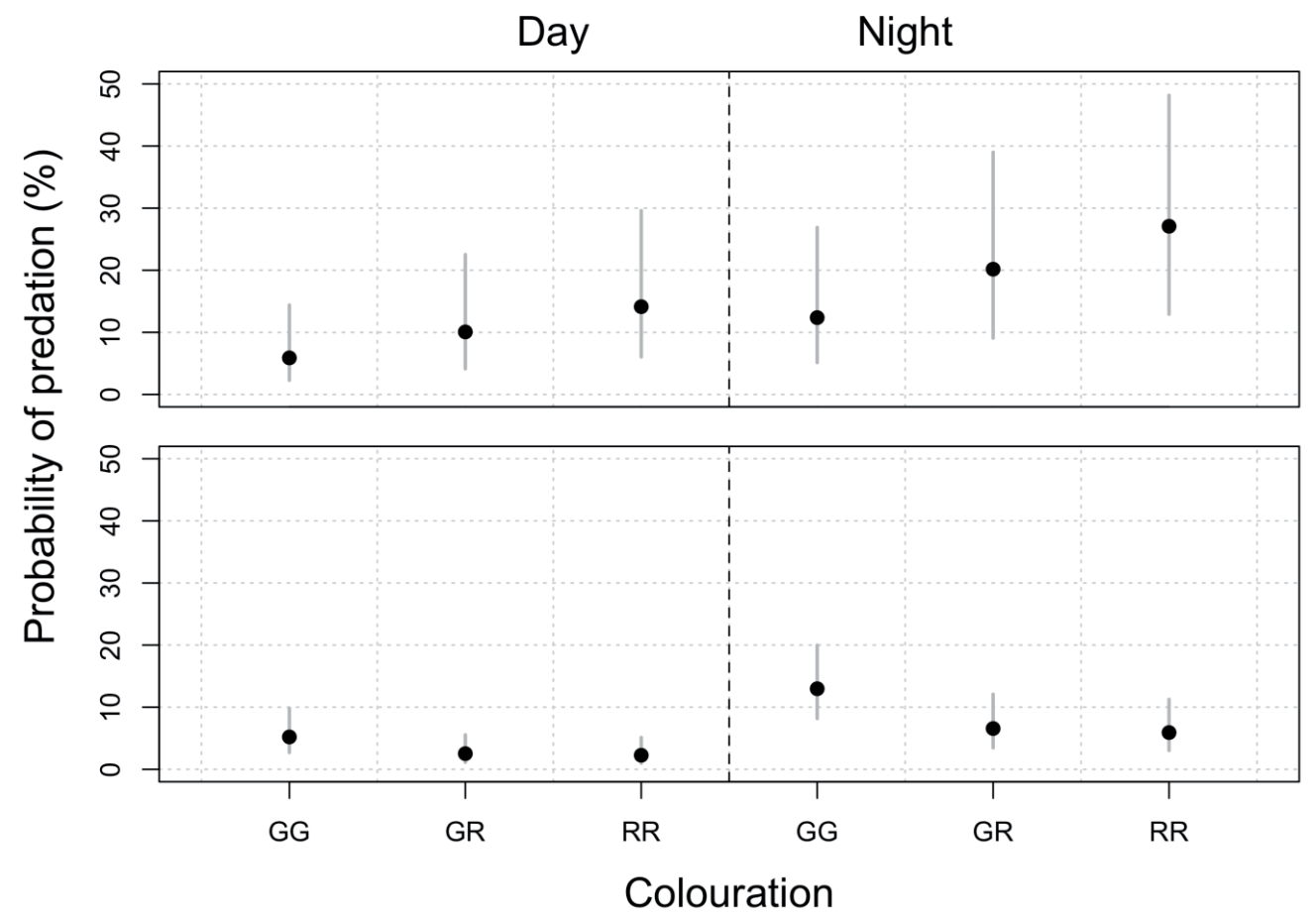

Figure 2. Logistic regression models output. Predicted mean values (circles) and confidence intervals from the logistic regression for invertebrate (top panel) and vertebrate (bottom panel) predation rates in deciduous forest fragments near Flakkebjerg, Denmark. 
common predators (Seifert et al. 2016). Ants are also important predators in lowland Papua New Guinea, responsible for $58 \%$ of the registered attacks (Tvardikova and Novotny 2012). The most common predators in our study were chewing insects and small mammals, both of which are usually more active at night than during the day. Most of the invertebrate marks found in our experiments were compatible with carabid mandible signs, and most carabids are night-active (Lövei and Sunderland 1996), readily attack artificial caterpillars (Ferrante et al. 2017), and their density correlates with attack rates in a nearby habitat (Mansion-Vaquié et al. 2017). While Seifert et al. (2016) claim that night activity provides caterpillars with enemy-free time, this may not be so, at least not on the ground in temperate forests.

We found that invertebrate and vertebrate predators reacted differently to prey colouration. Invertebrate predation was significantly higher on red-coloured prey. This can be explained because red colour appears as monochromatic green to most arthropods (Fabricant and Herberstein 2014) and thus may not act as aposematic colouration for invertebrate predators. Although none of the two coloured prey may have been perceived by invertebrate predators as aposematic, the red caterpillars may have been more detectable than the green ones, because of their greater contrast with the background. Most vertebrate predators, on the other hand, can see red colour (Yokoyama and Radlwimmer 2001), which is often an aposematic colouration for them (Sillén-Tullberg 1985). Vertebrate predation was higher (even if the difference was not statistically significant) on the green caterpillars. Similarly to our findings, predation by birds on aposematic vs. cryptic prey is not different in a temperate forest in Canada (Carroll and Sherratt 2013). Demonstrating the explanatory mechanism behind predation on differently coloured prey is challenging (Skelhorn et al. 2010), and was beyond the focus of this study. The interaction between colouration and exposure time was not significant in either invertebrate or vertebrate predation models, suggesting that the two factors are independent $(\mathrm{H} 2$ and $\mathrm{H} 3$ rejected). Evidence from real caterpillars also support the idea that defensive colouration may not necessarily predict their foraging behaviour (Mauricio and Bowers 1990).

Foraging behaviour is not only moulded by top-down forces (Edwards and Wratten 1983). Caterpillars are ectothermic organisms, and extreme temperatures may constrain their activity (Casey 1993), and/or may influence their physiology (e.g., digestion, growth rate) (Berger and Gotthard 2008). Moreover, caterpillars are under pressure to complete their development as fast as possible, and need to balance the predation risk vs. starvation (McNamara and Houston 1987).

Our results indicate that enemy-free time may actually not exist, or similarly to enemy-free space (Jeffries and Lawton 1984), absolute enemy-free time might be extremely rare in nature. We suggest that the two concepts should not be considered independently: enemy-free space may exist only at a certain time, and enemy-free time exists only in certain places.

Acknowledgements: We thank the Flakkebjerg Efterskole for permission to use their land and B. Bonafede and V. Bacle for help during field work. GL thanks P. Coley for introducing him to the artificial caterpillars. This is contribution no. 32 of the AMIGA Project, funded by the European Commission under grant agreement $\mathrm{n}^{\circ} 289706$, and is in partial fulfilment of the $\mathrm{PhD}$ requirements at Aarhus University, Denmark (MF). Author contributions: the study was designed by MF, GL, GB, and MV; field work was performed by MF, GB, MV, and $\mathrm{EB}$; data analysis by MF, GL, writing of the paper: MF, GL, with comments from all authors.

\section{References}

Akaike, H. 1998. Information theory and an extension of the maximum likelihood principle. In: E. Parzen, K. Tanabe, and G. Kitagawa (eds.), Selected Papers of Hirotugu Akaike. Springer, Berlin. pp. 199-213.

Aronsson, M. and G. Gamberale-Stille. 2009. Importance of internal pattern contrast and contrast against the background in aposematic signals. Behav. Ecol. 20:1356-1362.

Bates, D., M. Mächler, B. Bolker and S. Walker. 2015. Fitting linear mixed-effects models using lme4. J. Stat. Soft. 67:1-48.

Bereczki K., P. Ódor, G. Csóka, Z. Mag and A. Báldi. 2014. Effects of forest heterogeneity on the efficiency of caterpillar control service provided by birds in temperate oak forests. For. Ecol. Manage. 327:96-105.

Berger, D. and K. Gotthard. 2008. Time stress, predation risk and diurnal-nocturnal foraging trade-offs in larval prey. Behav. Ecol. Sociobiol. 62:1655-1663.

Cain, M.L. 1985. Random search by herbivorous insects: a simulation model. Ecology 66:876-888.

Carroll, J. and T. Sherratt. 2013. A direct comparison of the effectiveness of two anti-predator strategies under field conditions. $J$ Zool. 291:279-285.

Casey, T.M. 1993. Effects of temperature on foraging of caterpillars. In: Stamp, N.E. and T.M. Casey (eds.), Caterpillars: Ecological and Evolutionary Constraints on Foraging. Chapman \& Hall, New York. pp. 5-28.

Cronin, T.W., S. Johnsen, N.J. Marshall and E.J. Warrant. 2014. Visual Ecology. Princeton University Press, Princeton, NJ, USA.

Edwards, P. and S.D. Wratten. 1983. Wound induced defences in plants and their consequences for patterns of insect grazing. Oecologia 59:88-93.

Fabricant, S.A. and M.E. Herberstein. 2014. Hidden in plain orange: aposematic coloration is cryptic to a colorblind insect predator. Behav. Ecol. 26:38-44.

Ferrante, M., G. Barone and G.L. Lövei. 2017. The carabid Pterostichus melanarius uses chemical cues for opportunistic predation and saprophagy but not for finding healthy prey. BioControl 62:741-747.

Ferrante, M., A. Lo Cacciato and G.L. Lövei. 2014. Quantifying predation pressure along an urbanisation gradient in Denmark using artificial caterpillars. Eur. J. Entomol. 111:649-654.

Gittleman, J.L. and P.H. Harvey. 1980. Why are distasteful prey not cryptic? Nature 286:149-150.

Greeney, H., L. Dyer and A. Smilanich. 2012. Feeding by lepidopteran larvae is dangerous: A review of caterpillars' chemical, physiological, morphological, and behavioral defenses against natural enemies. Invert. Surviv. J. 9:7-34.

Heinrich, B. 1979. Foraging strategies of caterpillars. Oecologia 42: 325-337. 
Hossie, T.J. and T. N. Sherratt. 2012. Eyespots interact with body colour to protect caterpillar-like prey from avian predators. Anim. Behav. 84:167-173.

Hossie, T.J. and T. N. Sherratt. 2013. Defensive posture and eyespots deter avian predators from attacking caterpillar models. Anim. Behav. 86:383-389.

Hossie, T.J., J. Skelhorn, J.W. Breinholt, A. Y. Kawahara and T.N. Sherratt. 2015. Body size affects the evolution of eyespots in caterpillars. Proc. Natl. Acad. Sci. USA 112:6664-6669.

Howe, A., G.L. Lövei and G. Nachman. 2009. Dummy caterpillars as a simple method to assess predation rates on invertebrates in a tropical agroecosystem. Entomol. Exp. Appl. 31:325-329.

James, D.G., S. Morgan and A. Sourakov. 2017. The Book of Caterpillars: A Life-Size Guide to Six Hundred Species from around the World. Ivy Press, Brighton, U.K.

Jeffries, M. and J.H. Lawton. 1984. Enemy free space and the structure of ecological communities. Biol. J. Linn. Soc. 23:269-286.

Jones, R. 1977. Search behaviour: a study of three caterpillar species. Behaviour 60:237-259.

Kelbert, A. and L.S.V. Roth. 2006. Nocturnal colour vision - not as rare as we might think. J. Exp. Biol. 209:781-788.

Kenne, M. and A. Dejean. 1999. Diet and foraging activity in Myrmicaria opaciventris (Hymenoptera: Formicidae: Myrmicinae). Sociobiology 33:171-184.

Lövei, G.L. and M. Ferrante. 2017. A review of the sentinel prey method as a way of quantifying invertebrate predation under field conditions. Insect Sci. 24:528-542.

Lövei, G.L. and K.D. Sunderland. 1996. Ecology and behavior of ground beetles (Coleoptera: Carabidae). Annu. Rev. Entomol. 41: 231-256.

Low, P.A., K. Sam, C. McArthur, M.R.C. Posa and D.F. Hochuli. 2014. Determining predator identity from attack marks left in model caterpillars: guidelines for best practice. Entomol. Exp. Appl. 152:120-126.

Mansion-Vaquié A., M. Ferrante, S. Cook, J. Pell and G.L. Lövei 2017. Manipulating field margins to increase predation intensity in fields of winter wheat (Triticum aestivum). J. Appl. Entomol. 141:600-611.

Mauricio, R. and M.D. Bowers. 1990. Do caterpillars disperse their damage? Larval foraging behaviour of two specialist herbivores, Euphydryas phaeton (Nymphalidae) and Pieris rapae (Pieridae). Ecol. Entomol. 15:153-161.

McNamara, J.M. and A.I. Houston. 1987. Starvation and predation as factors limiting population size. Ecology 68:1515-1519.

Menzi, U. 1987. Visual adaptation in nocturnal and diurnal ants. $J$. Comp. Physiol. A. 160:11-21.

Mira, A. and E.A. Bernays. 2002. Trade-offs in host use by Manduca sexta: plant characters vs natural enemies. Oikos 97:387-397.

Mäntylä, E., G.A. Alessio, J.D. Blande, J. Heijari, J.K. Holopainen, T. Laaksonen, P. Piirtola and T. Klemola. 2008. From plants to birds: higher avian predation rates in trees responding to insect herbivory. PLoS One 3:e2832.

Mäntylä, E., J.D. Blande, and T. Klemola. 2014. Does application of methyl jasmonate to birch mimic herbivory and attract insectivorous birds in nature? Arthropod-Plant Interact. 8:143-153.

New, T.R. 2013. Lepidoptera and Conservation. John Wiley \& Sons, Hoboken, NJ, USA.

Novotny, V., Y. Basset, J. Auga, W. Boen, C. Dal, P. Drozd, M. Kasbal, B. Isua, R. Kutil and M. Manumbor. 1999. Predation risk for herbivorous insects on tropical vegetation: a search for enemy-free space and time. Austral Ecol. 24:477-483.

Opitz, S.E. and C. Müller. 2009. Plant chemistry and insect sequestration. Chemoecology 19:117-154.

R Core Team. 2015. R: A language and environment for statistical computing. R Foundation for Statistical Computing, Vienna, Austria. https://www.R-project.org/

Remmel, T., J. Davison and T. Tammaru. 2011. Quantifying predation on folivorous insect larvae: the perspective of life-history evolution. Biol. J. Linn. Soc. Lond. 104:1-18.

Rowland, H.M., I.C. Cuthill, I.F. Harvey, M.P. Speed and G.D Ruxton. 2008. Can't tell the caterpillars from the trees: countershading enhances survival in a woodland. Proc. Roy. Soc Lond. B. 275:2539-2545.

Rowland, H.M., M.P. Speed, G.D. Ruxton, M. Edmunds, M. Stevens and I.F. Harvey. 2007. Countershading enhances cryptic protection: an experiment with wild birds and artificial prey. Anim. Behav. 74:1249-1258.

Ruxton, G.D., T.N. Sherratt and M.P. Speed. 2004. Avoiding Attack: The Evolutionary Ecology of Crypsis, Warning Signals and Mimicry. Oxford: Oxford University Press, Oxford, U.K.

Salcedo, E., L. Zheng, M. Phistry, E.E. Bagg and S.G. Britt. 2003 Molecular basis for ultraviolet vision in invertebrates. $J$. Neurosci. 23:10873-10878.

Seifert, C.L., C.H. Schulze, T.C. Dreschke, H. Frötscher and K. Fiedler. 2016. Day vs. night predation on artificial caterpillars in primary rainforest habitats - an experimental approach. Entomol. Exp. Appl. 158:54-59.

Sillén-Tullberg, B. 1985. Higher survival of an aposematic than of a cryptic form of a distasteful bug. Oecologia 67:411-415.

Skelhorn, J., H.M. Rowland, M. P. Speed and G.D. Ruxton. 2010. Masquerade: camouflage without crypsis. Science 327:51-51.

Stevens, M. and G.D. Ruxton. 2012. Linking the evolution and form of warning coloration in nature. Proc. Roy. Soc. Lond. B. 279: $417-426$

Suzuki, T.N. and R. Sakurai. 2015. Bent posture improves the protective value of bird dropping masquerading by caterpillars. Anim. Behav. 105:79-84.

Théry, M. and D. Gomez. 2010. Insect colours and visual appearance in the eyes of their predators. Adv. Insect Physiol. 38:267-353.

Tvardikova, K. and V. Novotny. 2012. Predation on exposed and leaf-rolling artificial caterpillars in tropical forests of Papua New Guinea. J. Trop. Ecol. 28:331-341.

Warrant, E. and M. Dacke. 2011. Vision and visual navigation in nocturnal insects. Annu. Rev. Entomol. 56:239-254.

Yang, A.S. 2001. Modularity, evolvability, and adaptive radiations: a comparison of the hemi-and holometabolous insects. Evol. Dev. 3:59-72.

Yokoyama, S. and F.B. Radlwimmer. 2001. The molecular genetics and evolution of red and green color vision in vertebrates. Genetics 158:1697-1710.

Received June 15, 2017

Revised November 12, 2017

Accepted December 10, 2017

\section{Electronic Appendix}

Appendix A1. Description of the pilot experiment. 
Figure S1. Experimental design. Arrangement of the artificial caterpillar patch during the predator exposure experiments during the summer 2015, in Flakkebjerg, Denmark.

Figure S2. Red + black artificial caterpillar. Striped red + black caterpillar exposed to predators on ground-level during the summer 2017, in Flakkebjerg, Denmark.

Table S1. Logistic regression outcome for invertebrate predation. Effect of exposure time (day/night) and colour pair types (GG, GR, RR) on the incidence of invertebrate predation on artificial caterpillars in Flakkebjerg, Denmark, analysed using a logistic regression. The levels "Day" and "GG" served as bases for comparison.

Table S2. Logistic regression outcome for vertebrate predation. Effect of exposure time (day/night) and colour pair types (GG, GR, RR) on the incidence of vertebrate predation on artificial caterpillars in Flakkebjerg, Denmark, analysed using a logistic regression. The levels "Day" and "GG" served as bases for comparison.

The file may be downloaded from www.akademiai.com. 